\title{
Is Saddle block superior to spinal anaesthesia for patients undergoing transurethral resection of prostate- a comparative evaluation
}

\author{
Kirti Kshetrapal ${ }^{1}$, Priyanka Mishra ${ }^{2}$, Hemant Kamal ${ }^{3}$, Priyanka Bansal ${ }^{4}$ \\ ${ }^{1}$ Professor, ${ }^{2} P G$ Resident, ${ }^{4}$ Associate Professor, Department of Anaesthesiology, ${ }^{3}$ Senior Professor, Department of \\ Urology, PGIMS, Rohtak
}

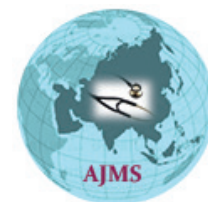

\section{A B S T R A C T}

Background: TURP is the most common surgical intervention for patients with benign prostatic hyperplasia. Aims and Objectives: This prospective randomized study was planned to evaluate spinal anaesthesia (SA) versus saddle block with regard to haemodynamic parameters, ephedrine consumption, patient and surgeon satisfaction, perioperative complications in patients undergoing TURP. Materials and Methods: Eighty patients between the ages of $50-80$ years with $\mathrm{BPH}$, belonging to ASA grade I- III, prostatic volume between 50 - $80 \mathrm{cc}$ were included in our study. Patients were randomly divided into two groups of 40 patients each. Patients in group SA $(n=40)$ received spinal anaesthesia and the patients in group SBBI $(n=40)$ were given saddle block with bladder instillation of local anaesthetic jelly for undergoing TURP. Results: There was more statistically significant fall in MAP in Group SA as compared to Group SBBI $(p<0.05)$. Complications like hypotension, bradycardia and vasopressor requirement was less but requirement $(p=0.021)$ of supplemental analgesia was more in patients who were administered saddle block. There was significantly lower patient satisfaction in saddle block $(p=0.044)$ but comparable surgical satisfaction in both groups. Conclusion: Both Spinal anaesthesia and saddle block are safe and effective techniques of anaesthesia for patients undergoing TURP. SA has advantages like less requirement of supplemental analgesia, longer duration of post-operative analgesia and more patient satisfaction. However, saddle block is superior to spinal anaesthesia with regard to haemodynamic stability; with less chances of hypotension, bradycardia and less vasopressor requirement. It is similar to SA in terms of providing adequate surgical conditions.
Access this article online

\section{Website:}

http://nepjol.info/index.php/AJMS DOI: $10.3126 /$ ajms.v12i10.38300

E-ISSN: 2091-0576

P-ISSN: 2467-9100

Copyright (c) 2021 Asian Journal of Medical Sciences

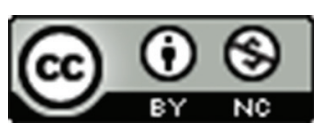

This work is licensed under a Creative Commons Attribution-NonCommercial 4.0 International License.

Key words: Sacral block; Spinal block; Transurethral resection of prostrate

\section{INTRODUCTION}

Benign Prostatic Hypertrophy is defined as a quality of life disorder that interferes with normal activities and symptoms occur in $40 \%$ to $80 \%$ of men after age of 60 years and by 80 years respectively.

Transurethral resection of prostate (TURP) is the most common surgical intervention for patients with benign prostatic hyperplasia. It is performed by inserting a resectoscope through the urethra and resecting prostatic tissue with an electrically powered cutting-coagulating metal loop or using laser- vaporization energy. With each technique, as much prostatic tissue as possible is resected, but the prostatic capsule is usually preserved. As the prostate gland contains large venous sinuses, it is inevitable that irrigating solution would be absorbed. Increased venous return due to lithotomy position may aggravate the chance of circulatory overload due to excessive absorption of irrigation solution through open prostatic venous sinuses during the surgical procedure. ${ }^{1}$ These patients are particularly vulnerable to volume overload as most of them belong to elderly age group and suffer from cardiopulmonary disorders. Spinal anaesthesia leads to peripheral pooling of blood, thus reducing the chances of circulatory overload and helps in 
early detection of complications like TURP syndrome and bladder perforation. TURP syndrome is a constellation of symptoms caused by the absorption of hypotonic bladder irrigants. Cardiovascular and neurologic changes are due to hypoosmolality, hyponatremia, hyperglycinemia, hyperammonemia, and hypervolemia.The major problem of spinal technique is the risk of hypotension. In spinal anesthesia due to sympathetic blockade, there is vasodilatation leading to diminished venous return which is the main contributory factor for hypotension. But the liberal use of i.v fluid is dangerous particularly in elderly patients with compromised cardiopulmonary function. ${ }^{1,2}$

Spinal anaesthesia is the technique of choice in TURP. ${ }^{2}$ Spinal anaesthesia produces sympathetic, sensory and motor blockade depending on dose, concentration and volume of drug injected. It requires a small volume of local anaesthetic to produce profound sensory analgesia and regardless of the anaesthetic agent (drug) used, the desired effect is to block the transmission of afferent nerve signals from peripheral nociceptors. ${ }^{3}$

Considering the innervation of prostate, height of subarachnoid block up to $\mathrm{T}_{10}$ is sufficient for TURP. ${ }^{2}$ Satisfactory regional anaesthesia for TURP involves achieving an anaesthetic block level that interrupts sensory transmission from the prostate and bladder neck. Sensory levels above $\mathrm{T} 9$ should not be sought because the capsular sign (i.e. pain on perforation of the prostatic capsule) would not be seen in case perforation occurs.

Saddle block blocks the sacral nerve roots and relaxes pelvic muscles and is denser in sacral, lumbar and lower thoracic dermatomes. As lower level of block is achieved, the hemodynamic derangement and chance of circulatory overload is less. Hence, Saddle block is more selective form of spinal anaesthesia. ${ }^{2}$ General anaesthesia may be necessary in patients who have a contraindication to regional anaesthesia, refuse to receive regional anaesthesia, having respiratory compromise or hemodynamic instability. ${ }^{1}$ Reports from previous studies on performing TURP under local anaesthesia is documented. Certain studies have combined perineal infiltration of local anaesthetic with an endoscopic intravesical block for performing TURP. ${ }^{3,4}$ Bupivacaine is an amide local anaesthetic that has been used for infiltration, nerve block, epidural and spinal anaesthesia since a long duration. ${ }^{5}$

Considering all these merits and demerits of regional block, the aim of our study is to compare the hemodynamic changes, vasopressor requirement and adequate surgical condition between saddle block and subarachnoid block for Transurethral resection of prostate (TURP).

\section{MATERIALS AND METHODS}

This prospective randomized comparative study was conducted in the department of Anaesthesiology and Critical care, Pt. B.D. Sharma PGIMS, Rohtak, after consent from Institutional ethics Committee. Eighty patients Aged between 50-80 years, belonging to American Society of Anesthesiologists (ASA) physical status I-II-III, with duration of surgery approximately 40-90 minutes and a prostatic volume of 50-80 cc, undergoing TURP for benign hyperplasia of prostate were included in this study.

Patients having Contraindications for regional anaesthesia (local site infections, coagulopathy, neurological, an allergy to amide local anaesthetics and refusal to participate in the study were not included in the study.

\section{Preparation of patient}

All the patients were subjected to detailed history, complete physical as well as systemic examination before surgery. Patient's age, weight, height and prostate volume were recorded. Routine investigations such as haemoglobin, bleeding time, clotting time, urine examination, blood urea, blood sugar, renal function tests, serum electrolytes, chest X-ray, electrocardiograph and rest all relevant investigations as per patient requirement were done. The purpose and protocol of the study was explained to patients and informed written consent was obtained. Patient were familiarized with Visual Analogue Scale (VAS) where 0 represents no pain while 10 represents worst pain imaginable. ${ }^{7}$ Upon arrival in operating room, routine monitoring including non-invasive blood pressure (NIBP), ECG and pulse oximetry $\left(\mathrm{SpO}_{2}\right)$ were attached. Intravenous line was secured with $18 \mathrm{G}$ venous cannula. Vital signs were recorded initially and after drug administration.

\section{Anaesthesia technique}

The study population was randomly (using computer generated list of random numbers) allocated into following two groups-

Group SA $(\mathrm{n}=40)$ were given spinal anaesthesia with $2 \mathrm{ml}$ hyperbaric bupivacaine. Group SBBI $(n=40)$ were given saddle block with $1.4 \mathrm{ml}$ of hyperbaric bupivacaine and bladder instillation of local anaesthetic jelly was done.

While maintaining all aseptic conditions, Lumbar puncture was done with 25 gauze disposable Quincke's needle at L3-L4 inter-vertebral space via midline approach in sitting position in both groups. After ensuring free flow of cerebrospinal fluid: Group SA ( $\mathrm{n}=40)$ received $2 \mathrm{ml}$ of $0.5 \%$ bupivacaine (Hyperbaric) and then were laid supine 
with one pillow under the head. The surgery was allowed to commence when the height of sensory block reached $\mathrm{T}_{10}$ dermatome.

Group SBBI $(\mathrm{n}=40)$ received $1.4 \mathrm{ml}$ of $0.5 \%$ bupivacaine (Hyperbaric) and were kept in the sitting position for 10 minutes and then laid supine with one pillow under the head. Per urethral 2\% lignocaine jelly was instilled and penile clamp was applied for 5 minutes. The level of sensory block was assessed for temperature by cotton wool soaked in ethyl alcohol. Height of the block was noted by continuously moving cephalad in the mid-clavicular line. Levels of dermatomes are as follows-

Dermatome Level ${ }^{8}$

$\mathrm{T}_{4} \quad$ nipples

$\mathrm{T}_{6}^{4} \quad$ xiphoid process

$\mathrm{T}_{8} \quad$ midway between xiphoid process and umbilicus

$\mathrm{T}_{10} \quad$ umbilicus

$\mathrm{T}_{11} \quad$ midpoint between umbilicus and inguinal ligament

$\mathrm{L}_{1} \quad$ midpoint of inguinal ligament

$\mathrm{S}_{3-5}$ perianal area

Motor block was tested using modified Bromage scale as: $0=$ no block, $1=$ inability to raise the extended leg, $2=$ inability to flex the knee, $3=$ inability to flex the ankle joint or great toe. If patient complained of pain or discomfort intra-operatively, fentanyl $\left(1 \mathrm{mcg} \mathrm{kg}^{-1}\right)$ was given. If the patient still complained of pain, the surgery would have been further continued under general anaesthesia and the patients would not have been included in the study. During the intra operative period, supplemental oxygen at the rate of $3 \mathrm{~L} \mathrm{~min}^{-1}$ was given to the patients.

Following observations were recorded- Baseline Systolic blood pressure(SBP), Diastolic blood pressure(DBP) and Mean arterial pressure (MAP), Heart Rate (HR), oxygen saturation (SpO2) were monitored continuously and recorded before and after administration of the drug and then at 5 minutes interval for half an hour and every $10 \mathrm{~min}$ for next 90 minutes, sensory block and motor block level, Duration of surgery(calculated from the time of insertion of resectoscope till it was taken out after the completion of surgery), peri-operative complications, if any were noted and managed accordingly. If any episode of hypotension occurred [decrease in Mean arterial pressure (MAP) more than $20 \%$ of the baseline value] i.v ephedrine at a dose of $3 \mathrm{mg}$ bolus was given and repeated if required. Total episodes of hypotension and ephedrine consumption were also recorded. If bradycardia (Heart rate less than $20 \%$ of the baseline value) occurred, it was managed by giving i.v atropine. Duration of post-operative analgesia was assessed and Inj. Tramadol $(1-2 \mathrm{mg} / \mathrm{kg})$ was given as per surgical unit protocol when VAS became $\geq 4$. Pre- operative and post-operative serum sodium values were evaluated. Patient's satisfaction was assessed by asking if he had any intraoperative discomfort and acceptance of same anaesthetic technique for future. Surgeon's satisfaction criteria included the surgical field bleeding, immobility of patient, degree of pelvic muscle relaxation.

\section{Sample size}

The primary objective of the study was to compare in terms of haemodynamics, subarachnoid block with saddle block in patients undergoing TURP surgeries. With 38 patients in each group, there was $80 \%$ power at an alpha 0.05 to detect a 25\% reduction in the incidence of hypotension and bradycardia between two groups, where we chose a $40 \%$ baseline ratio of incidence of hypotension and bradycardia based on a previous study in patients who were to undergo TURP surgeries. All consecutive patients meeting the eligibility criteria during the study period were enrolled. It was expected from the previous experience that about 40 patients per group would be enrolled.

\section{Statistical methods}

Statistical testing was conducted with the statistical package for the social science system version SPSS 17.0. Continuous variables were presented as mean $\pm \mathrm{SD}$ or median (IQR) for non-normally distributed data. Categorical variables were expressed as frequencies and percentages. The comparison of normally distributed continuous variables between the groups was performed using Student's t test. Nominal categorical data between the groups was compared using Chi-squared test or Fisher's exact test as appropriate. Nonnormal distribution continuous variables were compared using Mann Whitney $\mathrm{U}$ test. For all statistical tests, a $\mathrm{p}$ value less than 0.05 was taken to indicate a significant difference.

\section{RESULTS}

A total of 80 male patients were included and analysed statistically. The mean age, weight, BMI and ASA status were comparable between the two groups (Table 1). The baselines SBP, DBP, MAP were comparable (Table 2). On comparing the two groups after the procedure, the patients in group SA had considerably lower SBP, DBP and MAP than in SBBI group throughout the procedure though not significant statistically. Hypotension requiring ephedrine administration was higher in group SA than SBBI (p value $<0.001)$. Episodes of bradycardia were more in spinal anaesthesia group (Table 3). Serum sodium levels after the procedure were comparable between the two groups (Table 3). Duration of postoperative analgesia was more in SA group and it was significant $(\mathrm{p}<0.0001)$. Thus more number of patients in SBBI group required supplemental 


\begin{tabular}{|c|c|c|c|c|}
\hline & & $\begin{array}{c}\text { Group } \\
S B(n=40)\end{array}$ & $\begin{array}{c}\begin{array}{c}\text { Group SBBI } \\
(n=40)\end{array} \\
\end{array}$ & $p$ value \\
\hline 1 & $\begin{array}{l}\text { Duration of } \\
\text { surgery (mean } \\
\pm S D \text { ) }\end{array}$ & $59.25 \pm 12.48$ & $58.29 \pm 13.21$ & 0.738 \\
\hline \multirow[t]{3}{*}{3} & $\begin{array}{l}\text { Incidence of } \\
\text { Hypotension }\end{array}$ & & & \\
\hline & No & 30 & 39 & $<0.001$ \\
\hline & Yes & 10 & 1 & \\
\hline \multirow[t]{3}{*}{4} & $\begin{array}{l}\text { Requirement of } \\
\text { ephedrine }(\%)\end{array}$ & & & \\
\hline & Yes & 25 & 2.5 & $<0.001$ \\
\hline & No & 75 & 97.5 & \\
\hline \multirow[t]{3}{*}{5} & $\begin{array}{l}\text { Incidence of } \\
\text { bradycardia }\end{array}$ & & & \\
\hline & No & 33 & 39 & 0.025 \\
\hline & Yes & 7 & 1 & \\
\hline
\end{tabular}

\begin{tabular}{|c|c|c|c|}
\hline & Group SA & Group SBBI & $P$ value \\
\hline \multicolumn{4}{|l|}{ Heart rate $\left(\mathrm{min}^{-1}\right)$} \\
\hline \multicolumn{4}{|l|}{ SBP $(\mathrm{mmHg})$} \\
\hline baseline & $134.38 \pm 12.15$ & $134.3 \pm 9.10$ & 0.974 \\
\hline $\begin{array}{l}\text { Maximum fall } \\
\text { from baseline (at } \\
10-15 \text { mints of } \\
\text { block) }\end{array}$ & $19.35 \pm 1.92$ & $3.87 \pm 1.42$ & $<0.0001$ \\
\hline \multicolumn{4}{|l|}{ DBP } \\
\hline Baseline & $79.45 \pm 9.66$ & $78.93 \pm 7.01$ & 0.782 \\
\hline $\begin{array}{l}\text { Maximum fall } \\
\text { from baseline (at } \\
10-15 \text { mints of } \\
\text { block) }\end{array}$ & $10.6 \pm 1.20$ & $1.45 \pm 1.81$ & $<0.0001$ \\
\hline \multicolumn{4}{|l|}{ MAP } \\
\hline Baseline & $98.33 \pm 0.365$ & $96.63 \pm 0.875$ & 0.979 \\
\hline $\begin{array}{l}\text { Maximum fall } \\
\text { from baseline (at } \\
10-15 \text { mints of } \\
\text { block) }\end{array}$ & $11.45 \pm 0.42$ & $3.63 \pm 0.10$ & $<0.0001$ \\
\hline
\end{tabular}

analgesia $(\mathrm{p}=0.04)$. The patients were more satisfied with spinal than sacral block (Table 3). As far as the incidence of vomiting, the difference was insignificant $(\mathrm{p}=0.127)$

\section{DISCUSSION}

The advantages of spinal technique over general anesthesia are: less haemodynamic changes, it provides good postoperative analgesia, reduces blood loss during surgery and prevents the need for tracheal intubation that may irritate the airway. However, the hemodynamic changes are more gradual and of less magnitude with epidural technique but there is a chance of sacral sparing which may produce

\begin{tabular}{|c|c|c|c|c|}
\hline & & $\begin{array}{c}\text { Group SA } \\
\begin{array}{c}(n=40) \text { Mean } \\
\pm S D\end{array}\end{array}$ & $\begin{array}{l}\text { Group SBBI } \\
\begin{array}{c}(n=40) \text { Mean } \\
\pm S D\end{array}\end{array}$ & $P$ value \\
\hline \multirow[t]{3}{*}{1} & $\begin{array}{l}\text { Serum } \\
\text { Sodium levels } \\
\text { (meq/L) }\end{array}$ & & & \\
\hline & Preop & $143.40 \pm 4.14$ & $142.80 \pm 5.75$ & 0.596 \\
\hline & Postop & $138.05 \pm 5.45$ & $136.00 \pm 6.01$ & 0.112 \\
\hline \multirow[t]{3}{*}{2} & $\begin{array}{l}\text { Supplemental } \\
\text { analgesia } \\
(\%)\end{array}$ & & & \\
\hline & Yes & 0 & $12.5 \%$ & 0.021 \\
\hline & No & 100 & 87.5 & \\
\hline 3 & $\begin{array}{l}\text { Duration of } \\
\text { postoperative } \\
\text { analgesia }\end{array}$ & $232.75 \pm 25.56$ & $102.63 \pm 16.30$ & $<0.0001$ \\
\hline \multirow[t]{3}{*}{4} & $\begin{array}{l}\text { Patient } \\
\text { satisfaction }\end{array}$ & & & \\
\hline & No & 1 & 6 & 0.044 \\
\hline & Yes & 39 & 34 & \\
\hline
\end{tabular}

incomplete sacral nerve root block leading to inadequate surgical anesthesia. Saddle block offers definite anesthesia for prostate surgery with paralysis of the perineal muscles, anal sphincter and absence of lower limb paralysis or appreciable drop in blood pressure and heart rate from baseline. $^{8}$

The mean value of baseline SBP, DBP and MAP in group SA were 134.38 \pm 12.15 (Mean \pm SD) $\mathrm{mmHg}, 79.45 \pm$ $9.66 \mathrm{mmHg}$ and $98.33 \pm 0.365 \mathrm{mmHg}$ respectively. In this group, it was observed that the values were lower than the baseline value at all intervals. The average baseline SBP, DBP and MAP seen in group SBBI was $134.3 \pm 9.10 \mathrm{mmHg}$, $78.93 \pm 7.01 \mathrm{mmHg} 96.63 \pm 0.875 \mathrm{mmHg}$ respectively. In this group, a significant fall in SBP and DBP was noticed at 10 and 15 minutes following the block in both the groups. Our study is in line with the study done by Ozmen et al who compared the three different regional anaesthesia methods in patients who underwent TURP. They found that during the surgery, the SAP (systolic arterial pressure) values were stable in group SA (saddle). In Group E (epidural) and Group SP (spinal), there was a significant decrease in SAP values $(p<0.0001)$ relative to baseline values after the anaesthesia. ${ }^{6}$ Our results are also in consensus with the study conducted by Moosavi et al., who found that the intraoperative SBP values were most stable in group SA (saddle) as compared to spinal (SP) or epidural (E). ${ }^{7}$

Tiwari et al., who compared the changes in haemodynamic parameters resulting from subarachnoid block versus saddle block in patients posted for transurethral thulium laser prostatic ablation. They found the maximum change in MAP in group A (spinal) and B (saddle) was equal to $16.46 \pm 2.66 \mathrm{mmHg}$ and $8.90 \pm 1.56 \mathrm{mmHg}$ respectively. Our 
study showed the maximum fall in MAP in group SA and $\mathrm{SBBI}$ as $11.45 \pm 0.42$ and $3.63 \pm 0.10 \mathrm{mmHg}$ respectively. The comparative more fall in MAP in the saddle group in their study could be attributed to the higher dose of bupivacaine $(2 \mathrm{ml})$ used by them in contrast to our $1.4 \mathrm{ml}$ dose. ${ }^{9}$

In our study we have found that the maximum fall in group SA for SBP, DBP and MAP were $19.35 \pm 1.92 \mathrm{mmHg}$, $10.6 \pm 1.20 \mathrm{mmHg}$ and $11.45 \pm 0.42 \mathrm{mmHg}$ respectively. In group SBBI, the maximum decrease in SBP, DBP and in MAP was $3.87 \pm 1.42 \mathrm{mmHg}, 1.45 \pm 1.81 \mathrm{mmHg}$ and $3.63 \pm 0.10 \mathrm{mmHg}$ respectively. Our results are in concurrence to Bhattacharyya et al., who found that the maximum fall of SBP, DBP, MAP was more in patients who received spinal anaesthesia as compared to saddle block. ${ }^{8}$

The incidences of hypotension requiring ephedrine were 10 amongst those who received spinal anaesthesia and just one amongst the patients who received saddle. These results are consistent with the findings of Tiwari et al., who found the requirement of ephedrine was significantly less in the patients who received saddle block $(\mathrm{p}<0.0001)$ as compared to those receiving sub-arachnoid block. ${ }^{9}$ Bhattacharya et al also similarly found that phenylephrine consumption was significantly less in Group B (7.78 $\pm 2.60 \mu \mathrm{g})$ than Group A $(120 \pm 30.90 \mu \mathrm{g})$ which was statistically significant $(\mathrm{p}<0.0001){ }^{8}$

When the two groups were compared with each other, the HR values were significantly lower in the patients who were administered spinal anaesthesia $(\mathrm{p}<0.05)$ than those who received saddle block. Though there was a decrease in HR in nearly all the patients, bradycardia was seen in seven patients in group SA. There was a single episode of bradycardia with hypotension occurring five minutes after a patient was administered saddle block. These results are similar to those found in the study by Tiwari et al., where the intraoperative fall in HR was significantly less in the patients in Group B(saddle) compared to Group A (spinal) $(\mathrm{p}<0.0001)$. Our results are also similar to those found by Bhattacharya et al., where the fall of HR was significantly more $(p<0.0001)$ in spinal group than the saddle group. ${ }^{8,9}$

In contrast to our study, Ozmen et al., found a significant decrease $(p<0.05)$ in HR values within both the spinal and saddle groups 15 minutes after the block. ${ }^{6}$ The possible reason for this significant fall in $\mathrm{HR}$ at 15 minutes interval even in the saddle group could be due to the higher dose of intrathecal local anaesthetic used and hence, probably a higher level of blockade achieved by them.

There was a significant decrease in the post-operative sodium levels in comparison to pre-operative levels in both the groups in the present study $(\mathrm{p}<0.05)$. However, the two groups when compared with each other, the difference between the pre-operative ( $\mathrm{p}$ value $=0.596$ ) serum sodium and post-operative $(p$ value $=0.112)$ sodium levels was found to be insignificant. Our results are in consensus with the study conducted by Ozmen et al., who found that there was a statistically significant decrease in serum sodium values in all the groups (spinal, saddle and epidural) 1 hour after TURP $(\mathrm{p}<0.0001){ }^{6}$

Our study showed that none of the patients required supplemental analgesia in Group SA while in Group SBBI, five patients' required supplemental analgesia. The reason for pain and discomfort experienced by the patients can be due to the bladder distension. When compared statistically, the requirement of supplemental analgesia was significantly more $(\mathrm{p}$ value $=0.001)$ in those who received saddle block as compared to the patients who were administered spinal anaesthesia. This is in contrast to the studies done by Moosavi et al., and Ozmen et al., where there was no requirement of any supplemental analgesia. ${ }^{6,7}$ This difference could have been due to the addition of intrathecal opiod (fentanyl) in both these studies and a higher dose of local anaesthetic (10 $\mathrm{mg}$ bupivacaine) used in them.

The duration of post-operative analgesia was found significantly more $(\mathrm{p}$ value $<0.0001)$ in the patients who received spinal anaesthesia as compared to the patients who were administered saddle block. This difference could be due to higher level of block achieved in spinal anaesthesia and hence more time taken for the effect to recede. In a recent study by Bejoy et al., comparing the hemodynamic stability as well as the anaesthetic efficacy of subarachnoid block versus saddle block, patients received spinal or saddle block using the same volume $(2.5 \mathrm{ml})$ of hyperbaric bupivacaine, in patients undergoing TURP. There was a significant delay in saddle block patients to achieve T10 sensory level and the level of motor block was low according to modified bromage scale. ${ }^{10}$

The patients were more satisfied with spinal anaesthesia. The patient dissatisfaction seen in saddle group was mainly attributed to the discomfort due to bladder distension that got relieved after the administration of supplemental anaesthesia. Both saddle and subarachnoid block allowed successful surgery in all the cases and the surgeon satisfaction scores were comparable between the two groups. In contrast to our study, Tiwari et al., found that saddle block and spinal anaesthesia both provide adequate surgical conditions for transurethral thulium laser prostatic ablation. ${ }^{9}$ There were no other major complications seen in patients in either group. 
Our study was different than the others as all those studies comparing spinal anaesthesia versus saddle block have given $2 \mathrm{ml}(10 \mathrm{mg})$ of intrathecal hyperbaric bupivacaine and possibly got higher level of dermatomal block. We however have used $1.4 \mathrm{ml}(7 \mathrm{mg})$ of intrathecal hyperbaric bupivacaine that has resulted in effective block for successful TURP. There were few limitations in our study for example: a small sample size studied by us. A larger sample size could have helped us validate our results more emphatically. We did not calculate the amount of irrigation fluid absorbed. Though in saddle block, anaesthesia in perianal region was confirmed, we did not note the highest level of dermatomal block achieved. We further recommend that more studies be conducted employing lower doses of bupivacaine as used by us.

\section{CONCLUSION}

Both spinal anaesthesia and saddle block are simple and effective techniques of anaesthesia for patients undergoing TURP. Spinal anaesthesia has advantages like less requirement of supplemental analgesia, longer duration of post-operative analgesia and more patient satisfaction. However saddle block is superior to spinal anaesthesia with regard to haemodynamic stability. The surgical adequacy is comparable in both these techniques of anaesthesia. Hence, both saddle and spinal anaesthesia are safe and effective techniques of anaesthesia for TURP.

\section{REFERENCES}

1. Millers DR, Cohen NH, Erikkson IL et al. Anesthesia and the Renal and Genitourinary Systems. $8^{\text {th }}$ ed. Miller's
Anesthesia.2015.p.2217-43.2.

2. Miller $\mathrm{J}$ and Tarter TH. Combination therapy with dutasteride and tamsulosin for the treatment of symptomatic enlarged prostate. Clin Interv Aging. 2009; 4:251-258.

https://doi.org/10.2147/CIA.S4102

3. Tripathi DK. Local anesthetics. $6^{\text {th }}$ ed. Essentials of medical pharmacology.2009:354-357.

4. Malhotra V, Sudheendra, V, O'Hara J and Malhotra A. Anesthesia and the renal and genitourinary systems. In: Miller RD. editor. Miller's Anesthesia. $8^{\text {th }}$ ed. Philadelphia: Churchill Livingstone; 2015. p. 2217-43.

5. Obi AO and Nnodi PI. Low Dose Spinal Saddle Block Anesthesia For Transrectal Prostate Biopsy-Experience with 120 Cases. J Anesth Clin Res. 2014; 5:469.

https://doi.org/10.1016/j.juro.2014.02.1650

6. Ozmen S, Kosar A, Soyupek S, Armagan A, Hoşcan MB and Aydin C. The selection of regional anaesthesia in transurethral resection of the prostate (TURP) operation. Int Urol Nephrol.2003; 35:507-512.

https://doi.org/10.1023/B: UROL.0000025616.21293.6c

7. Moosavi T, Sharifian A and Asgharian N. The selection of regional anesthesia in transurethral resection of prostate (TURP). OFOGH-E-DANESH. 2006; 11:441-447.

8. Bhattacharyya S, Bisai S, Biswas A, Tiwary MK, Mallik S and Saha SM. Regional anesthesia in transurethral resection of prostate (TURP) surgery: A comparative study between saddle block and subarachnoid block. Saudi J Anaesth. 2015; 9:268-271.

https://doi.org/10.4103/1658-354X.158497

9. Tiwari D, Gehlaut P, Chhabra S and Ahlawat M. Subarachnoid block versus saddle block in going transurethral thulium laser prostatic Ablation: A comparative study. IJCR.2016; 8(02):2696326965.

10. Bejoy R, Thomas D and Beevi S. Saddle block versus subarachnoid block for transurethral resection of prostate surgery: A randomized comparative study. Bali J Anaesthesiol. 2020; 4:178-182.

https://doi.org/10.4103/BJOA.BJOA_120_20

\footnotetext{
Author's Contribution:

HK-Concept and design of the study; prepared first draft of manuscript; KK- Concept and design of the study; prepared first draft of manuscript, reviewed the literature and manuscript preparation; PM- Interpreted the results; reviewed the literature and manuscript preparation; PB- Concept, coordination, review of literature and manuscript preparation.

Work Attributed to:

PGIMS, Rohtak, India.

Orcid ID:

Dr Priyanka Bansal- (D https://orcid.org/0000-0002-5900-401X

Dr Priyanka Mishra- (i) https://orcid.org/0000-0002-1870-7923

Source of Funding: None, Conflict of Interest: None.
} 